\title{
INSTITUTIONAL FEATURES OF DIGITALIZATION OF RUSSIAN ECONOMY
}

\author{
Marina L. Alpidovskaya \\ Financial University under the Government of the Russian Federation, Moscow, Russian Federation \\ Ekaterina S. Stompeleva \\ Financial University under the Government of the Russian Federation, Moscow, Russian Federation
}

\begin{abstract}
The relevance of the research is caused by the importance of maintaining the competitiveness of the national economy in the conditions of forming and developing digital economy. The research objective is to analyze obstacles to the effective implementation of the strategy of digitalization of the domestic economy and factors that hinder it, which, in our opinion, are not given enough attention. The authors consider the influence of institutional features of modern Russian economy on economic behavior of business. The adverse institutional environment is considered the main reason which is slowing down digitalization of Russian economy and development of digital technologies by business. The analysis of the modern Russian institutional environment, in particular its important factors such as vulnerability of ownership rights and low institutional trust to the power, allows to draw the conclusion that they lead to the emergence and consolidation of new economic and behavioral norms, which become alternative mechanisms of the economic choice at implementing economic interests. The article substantiates such a modern phenomenon of Russian economy as institutional alienation of reproduction functions of business at the social production. In this connection, there is a necessary to develop state actions for digitalization of economy at their coordination with a complex of actions for improving the institutional business environment, which is slowing down effective socio-economic development of the national economy.

Key words: competitiveness of economy, digital economy, economic interests, socio-economic development, reproduction, institutional alienation.

Citation. Alpidovskaya M.L., Stompeleva E.S. Institutional Features of Digitalization of Russian Economy. Journal of Volgograd State University. Economics, 2020, vol. 22, no. 1, pp. 15-22. (in Russian). DOI: https://doi.org/ 10.15688/ek.jvolsu.2020.1.2
\end{abstract}

УДК $338.24(470+571)$

Дата поступления статьи: 19.11.2019

ББК 65.9(2)-21

Дата принятия статьи: 18.12.2019

\section{ИНСТИТУЦИОНАЛЬНЫЕ ОСОБЕННОСТИ ЦИФРОВИЗАЦИИ РОССИЙСКОЙЭКОНОМИКИ}

\author{
Марина Леонидовна Альпидовская
}

Финансовый университет при Правительстве Российской Федерации, г. Москва, Российская Федерация

\section{Екатерина Сергеевна Стомпелева}

Финансовый университет при Правительстве Российской Федерации, г. Москва, Российская Федерация

Аннотация. Актуальность исследования обусловлена важностью сохранения конкурентоспособности национальной экономики в условиях формирования и развития цифровой экономики. Целью данной работы является анализ препятствий эффективной реализации стратегии цифровизации отечественной экономики и тормозящих ее факторов, которым, на наш взгляд, уделяется недостаточно внимания. В статье рассматривается влияние институциональных особенностей современной российской экономики на хозяйственное 
поведение бизнеса. Неблагоприятная институциональная среда выделяется в качестве главной причины, тормозящей цифровизацию российской экономики и развитие бизнесом цифровых технологий. Анализ сложившейся в России институциональной среды, в частности таких ее факторов, как незащищенность прав собственности и низкое институциональное доверие к власти, позволяет сделать вывод о том, что они приводят к возникновению и закреплению новых хозяйственно-поведенческих норм, которые становятся альтернативными механизмами экономического выбора субъектов при реализации своих экономических интересов. В статье рассматривается такое современное явление российской экономики, как институциональное отчуждение бизнесом своих воспроизводственных функций в общественном производстве, в связи с чем необходима разработка комплекса государственных мероприятий по цифровизации экономики с учетом институциональной составляющей хозяйствования.

Ключевые слова: конкурентоспособность экономики, цифровая экономика, экономические интересы, социально-экономическое развитие, воспроизводство, институциональное отчуждение.

Цитирование. Альпидовская М. Л., Стомпелева Е. С. Институциональные особенности цифровизации российской экономики // Вестник Волгоградского государственного университета. Экономика. - 2020. - Т. 22, № 1. -C. 15-22. - DOI: https://doi.org/10.15688/ek.jvolsu.2020.1.2

Большинство исследователей сходится во мнении, что современная экономика - это цифровая экономика, представляющая собой качественно новый этап развития экономической системы, в котором происходит переход к VI технологическому укладу [Шваб, 2017]. Согласно определению Всемирного банка, цифровая экономика - это система социальных, экономических и культурных отношений, в основе которой лежит использование цифровых информационно-коммуникационных технологий [The World Bank]. Ценнейшим peсурсом данной экономики выступает информация, а преобладающая часть национального продукта обеспечивается в сферах, связанных с процессами производства, обработки, хранения и распространения информации.

В современных условиях уровень цифровизации экономики становится определяющим фактором ее конкурентоспособности, а главным драйвером роста конкурентоспособности бизнеса выступает внедрение им цифровых технологий. Вместе с тем развитие цифровой экономики в мире несет в себе как новые возможности, так и угрозы обеспечения конкурентоспособности национальных экономик. С одной стороны, цифровая экономика дает новые импульсы мировому экономическому развитию, формируя глобальное информационное пространство, нивелируя территориально-временные границы взаимодействия хозяйствующих субъектов, поставщиков и потребителей, существенно расширяя мирохозяйственные связи между ними. С другой стороны, распространение цифровых технологий создает такие материально-технические условия развития производства, в которых конкуренция становится все более интенсивной и глобальной, а поддержание конкурентоспособности национальной экономики - все более сложным процессом.

Острая необходимость масштабного внедрения цифровых технологий для создания инновационных материально-технических условий развития производства и реализации стратегии конкурентоспособности российской экономики общепризнана и уже несколько лет обсуждается в политических, деловых и научных кругах [Альпидовская, 2018]. Однако современные темпы и уровень развития инновационных технологий в России не соответствуют ожиданиям, связанным с формированием цифровой экономики. Это выдвигает на первый план необходимость анализа препятствий эффективной реализации стратегии цифровизации отечественной экономики и тормозящих ее факторов, которым, на наш взгляд, уделяется недостаточно внимания.

Текущий уровень использования достижений цифровой экономики в России позволяет говорить об активном применении инновационных цифровых технологий преимущественно в сферах обмена и потребления. При этом конкурентоспособность производимых национальной экономикой товаров, а следовательно, и самой экономики - это их способность отвечать требованиям конкурентного рынка по техническим, потребительским и ценовым свойствам, которые «закладываются» в товар не в процессе обмена, а до выхо- 
да товара на рынок, то есть в процессе его производства. Поэтому основой обеспечения конкурентоспособности экономики, на наш взгляд, является внедрение инновационных цифровых технологий именно в производственную сферу. В связи с этим обеспечение конкурентоспособности национальной экономики и препятствующие этому факторы предлагается проанализировать прежде всего в рамках производственного процесса.

Инновационная производственная деятельность подразумевает такие отношения между государством, бизнесом, научным сообществом и населением, где обеспечено их эффективное взаимодействие в процессе производства. Каждая из данных социально-экономических групп имеет свои задачи в этом взаимодействии и свои экономические интересы.

Главной задачей государства в данном взаимодействии является создание необходимых и достаточных институциональных и инфраструктурных условий для использования и развития цифровых технологий в производстве с целью повышения производительности труда. При этом наиболее важным аспектом выступает создание таких институциональных условий, которые будут учитывать интересы участников данного взаимодействия и способствовать их наиболее полной взаимной реализации.

Особая экономическая роль в рыночной экономике традиционно отводится бизнесу как непосредственно производственно-хозяйственному субъекту. С точки зрения экономики как воспроизводственной системы именно на него возложена общественная функция по непрерывному возобновлению общественного производства. Однако в российской экономике бизнес не выполняет присущие ему воспроизводственные задачи, в частности задачи по внедрению в производство инновационных цифровых технологий.

В настоящее время в научной литературе деформированное экономическое поведение российской бизнес-элиты в своей хозяйственной деятельности общепризнано. Осознанный «нигилизм» российского бизнеса по отношению к своим предприятиям отмечается также и на уровне официальных лиц. Глава Российского союза промышленников и пред- принимателей Александр Шохин в ходе выступления на Петербургском экономическом форуме 2019 г. отметил постоянно снижающуюся роль частного бизнеса в отечественной экономике при одновременном возрастании роли государства и государственных компаний [Фадеева и др.]. У частных инвесторов нет реальных стимулов вкладываться в национальные проекты, зато есть большая неопределенность относительно институциональной и регуляторной среды отечественной экономики [Фадеева и др.].

Это подтверждается данными хозяйственной практики, свидетельствующими об осознанном лишении отечественным бизнесом своих предприятий не только инвестиционных, но и оборотных средств, необходимых для выполнения ими текущих финансово-хозяйственных обязательств [Кричевский, 2009]. Так, например, в кризисный период большая часть крупнейших предприятий страны объявила о выплате дивидендов своим акционерам по итогам шести либо девяти месяцев 2008 г. [Кричевский, 2009]. В качестве главной причины такого хозяйственного поведения принято считать социально-экономическую природу действующей институциональной хозяйственной системы. И именно неблагоприятная институциональная среда выделяется в качестве главной причины, тормозящей цифровизацию российской экономики и развитие бизнесом цифровых технологий.

Среди ключевых факторов современной институциональной среды, создающих несобственническое хозяйственное поведение российского бизнеса, в научной литературе выделяют следующие:

- незащищенность прав собственности [Капелюшников, 2012];

- низкое институциональное доверие к власти [Экономические субъекты ..., 2010];

- неопределенность и непредсказуемость институциональной среды;

- наличие социального неприятия итогов приватизации [Капелюшников, 2012].

Современные статистические данные свидетельствуют о том, что незащчищенность прав собственности остается на первом месте в рейтинге влияния факторов институциональной среды на хозяйственное поведение бизнеса [Дергачев]. Так, обращения 
по поводу проявления рейдерства и других неправомерных действий по отношению к имуществу хозяйствующих субъектов стоит на первом месте в статистке официальных обращений бизнеса в Генпрокуратуру (табл. 1). Национальный антикоррупционный комитет оценивает объем рейдерских захватов в России в размере до 700 тыс. в год, из которых только в $10 \%$ заводятся уголовные дела [Воронина, 2015].

Непредсказуемость институциональной среды выделяют в качестве второго по значимости фактора, который беспокоит бизнес [Фадеева и др.]. В качестве конкретной проблемы, создающей неопределенность для бизнеса и тормозящей развитие цифровой экономики, выделяют до сих пор не принятый закон об инвестиционной деятельности в России, целью которого является установление четкого механизма привлечения частных инвестиций в национальные проекты и создание стимулов для участия в них [Фадеева и др.].

Если обращения, указанные в пунктах 2-5 таблицы 1, связанные с нарушением со стороны органов власти прав и интересов бизнеса, установленных действующими институтами, объединить в одну общую группу «низкое институциональное доверие к власти», то в процентном отношении значение данного фактора составит $64 \%$. Следовательно, данный фактор займет первое место в общем объеме обращений бизнеса и даже превысит количество обращений по поводу рейдерства.

Обозначенные факторы современной институциональной среды, представляющей собой совокупность политических, юридичес- ких и социальных институтов хозяйствования, не просто снижают инвестиционную активность отечественного бизнеса и сужают временной горизонт принимаемых им решений, а приводят к ситуации, когда экономические интересы и экономические потребности собственников реализуются преимущественно без связи с эффективностью производства как такового и в противоречии с национальными воспроизводственными процессами, обостряя тем самым воспроизводственные противоречия социально-экономической системы в целом [Стомпелева, 2017]. Это, на наш взгляд, подтверждает статистика по беспрецедентному по своим размерам оттоку частного капитала из страны, а также массированному выводу предпринимателями активов из собственного бизнеса и их последующему переводу в личные активы, который еще более усиливается в кризисные периоды (см. рисунок). Так, в 2008 и 2014 гг. в условиях падения объемов ВВП и доходов хозяйствующих субъектов отмечается резкий рост объема вывоза капитала из страны частным сектором.

Таким образом, особенности сложившейся российской институциональной среды приводят к возникновению и закреплению новых хозяйственно-поведенческих норм, которые становятся альтернативными механизмами экономического выбора субъектов при реализации своих экономических интересов.

Методологически следует различать институализацию экономических интересов как объективный механизм их реализации, который задан социально-экономической природой существующей хозяйственной системы,

Таблииа 1

Обращения российского бизнеса в Генпрокуратуру с 17.06 .2016 по 01.02.2017

\begin{tabular}{|c|c|c|c|}
\hline \multirow{2}{*}{$\begin{array}{l}\text { № } \\
\Pi / \Pi \\
\end{array}$} & \multirow{2}{*}{ Предмет обращения } & \multicolumn{2}{|c|}{ Количество обращений } \\
\hline & & шт. & $\%$ \\
\hline 1 & $\begin{array}{l}\text { Проявление рейдерства и других незаконных действий в отноше- } \\
\text { нии имущества хозяйствующих субъектов }\end{array}$ & 202 & 36 \\
\hline 2 & $\begin{array}{l}\text { Необоснованное уголовное преследование, заключение под стра- } \\
\text { жу и другие меры пресечения }\end{array}$ & 143 & \multirow{4}{*}{64} \\
\hline 3 & $\begin{array}{l}\text { Нарушение порядка предоставления публичных услуг, размеще- } \\
\text { ния заказов для публичных нужд }\end{array}$ & 123 & \\
\hline 4 & Нарушение порядка проведения проверок & 60 & \\
\hline 5 & Необоснованное принятие мер административного принуждения & 29 & \\
\hline 6 & Bcero & 557 & 100 \\
\hline
\end{tabular}

Примечание. Составлено авторами на основании данных Генпрокуратуры Российской Федерации (см.: [Дергачев, 2017]). 
и институц̧ионализацию экономических интересов как процесс проектирования структуры разноуровневых статусов, норм и ролей и приведения их в систему, которая способна действовать в направлении эффективного социально-экономического развития [Карасева, 2018]. Это позволяет анализировать ключевые проблемы современной российской экономики через призму несоответствия отечественной институциональной среды объективной системе экономических интересов.

В российской экономике действующая институциональная среда не способствует институционализации экономических интересов бизнеса в направлении национального социально-экономического развития. Собственники отечественного бизнеса лишены характерных для них экономических функций, а экономическое поведение и реальные интересы данных субъектов не соответствуют их институциональному положению и объективным экономическим функциям [Стомпелева, 2017].

Результатом институализации экономических интересов российского бизнеса как субъекта цифровой экономики в форме новых хозяйственно-поведенческих норм, соответствующих особенностям институциональной системы, является деформация объективного содержания их экономических интересов, отчуждение своих объективных воспроизводственных функций и антисистемный характер хозяйственного поведения, когда экономические интересы и экономические потребности реализуются преимущественно без связи с общественным производством. Понятие «отчуждение» используется здесь в общефилософском контексте - как характеристика такой формы взаимоотношения человека с окружающим миром в процессе его жизнедеятельности, при которой продукты деятельности и сама деятельность противостоят человеку как нечто чуждое ему. При этом данное отчуждение у бизнеса своих объективных воспроизводственных функций в социально-экономических системе можно охарактеризовать особым видом отчуждения - институциональным отчуждением. Институцииональное отчуждение характеризуется противопоставлением институтов человеку в его хозяйственной деятельности, которое традиционно рассматривается как процесс, в рамках которого «безличные социальные структуры превращаются в активное начало, становятся субъектом социальной деятельности, низводя отдельного человека до уровня орудия, средства поддержания “жизни” этих социальных структур» [Кириленко и др., 2010, с. 265].

Таким образом, институциональное отчуждение субъектами своих объективных экономических интересов и воспроизводственных функций представляет собой способ воспроизводства (существования) хозяйствующих субъектов в действующей институциональной среде и отражение субъективного осознания субъектами своих экономических интересов с учетом действующих институтов, закрепляющих допустимые общественные условиях реализации этих интересов (см. табл. 2).

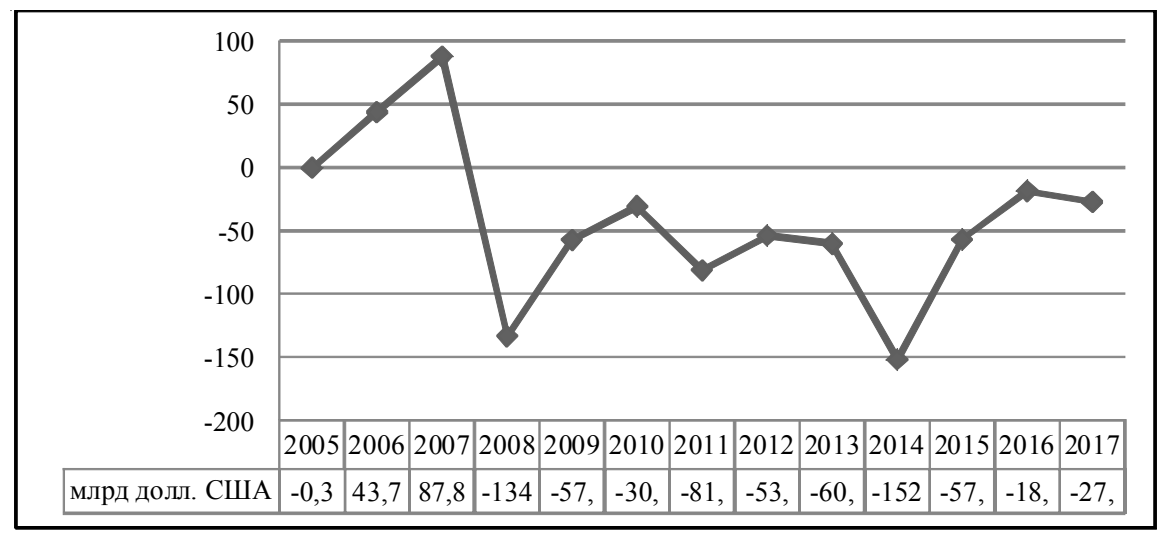

Рисунок. Чистый ввоз (+) / вывоз (-) капитала частным сектором в 2005-2017 гг.

Примечание. Составлено авторами по: [Заключение Счетной палаты ... , 2018]. 


\section{ЭКОНОМИЧЕСКАЯ ТЕОРИЯ}

В сложившихся условиях реализация стратегии цифровизации российской экономики, направленная на повышение ее конкурентоспособности, становится невозможной без соответствующих мероприятий по институционализации российской системы экономических интересов, которая способна действовать в направлении эффективного социально-экономического развития национальной экономики.

Для реализации цифровой стратегии в конце 2018 г. была принята государственная программа «Цифровая экономика Российской Федерации» как национальный проект, реализация которого рассчитана по 2024 г. с бюджетом в 1,79 млрд рублей. Наибольшая часть бюджета данного национального проекта (около $43 \%$ от общего объема финансирования) предусмотрена на создание и развитие инфраструктуры цифровой экономики в рамках федерального проекта «Информационная инфраструктура», а $25 \%$ - на создание цифровых технологий.

В качестве основных показателей результативности данного национального проекта указаны такие индикаторы, как: внутренние затраты на развитие цифровой экономики за счет всех источников по доле в валовом внутреннем продукте страны; доля субъектов экономики, имеющих доступ к сети Интернет; стоимостная доля закупаемого и / или арендуемого государственными органами власти и государственными корпорациями отечественного программного обеспечения.

Как видно, данные показатели характеризуют в основном объем государственных затрат и частных инвестиций в развитие цифровой экономики. При этом программа не раскрывает конкретные социальные и экономические показатели эффективности этих затрат, не обосновывает их увязку с ростом про- изводительности труда и удовлетворением потребностей населения страны. Такая цель, как увеличение количественных показателей затрат, сама по себе может не дать ожидаемый социально-экономических эффект, а может даже привести к ущербу и для самого производства, и для населения, и для окружающей природы. Для целей социально-экономического развития важнейшими критериями наряду с количественными показателями становятся качественные характеристики такого развития [Альпидовская, 2017]. Но они в национальной программе «Цифровая экономика Российской Федерации» отсутствуют.

Кроме того, без соответствующей мотивации бизнеса на осуществление инвестиций в области цифровых технологий, без улучшения институциональной среды хозяйствования и повышения институциональной доверия к власти государственные мероприятия и затраты не будут способствовать национальным воспроизводственным процессам. Следовательно, в условиях существующего институционального отчуждения бизнесом своих воспроизводственных функций вопрос о разработке государством мероприятий по цифровизации экономики, взаимоувязанных с комплексом мероприятий по улучшению институциональной среды хозяйствования, направленных на социально-экономическое развитие и повышение конкурентоспособности российской экономики, остается открытым и актуальным.

\section{СПИСОК ЛИТЕРАТУРЫ}

Альпидовская, М. Л. Конкурентоспособность национальной экономики: стратегии развития : монография / М. Л. Альпидовская, А. М. Цикин. - Тверь : Твер. гос. ун-т, 2018. - 192 с.

Таблица 2

Особенности экономических и хозяйственных интересов бизнеса как субъекта цифровой экономики

\begin{tabular}{|c|c|c|c|c|}
\hline \multirow[b]{2}{*}{ Субъект } & \multicolumn{2}{|c|}{ Объективный уровень } & \multicolumn{2}{|c|}{ Субъективный хозяйственный уровень } \\
\hline & $\begin{array}{c}\text { Экономический } \\
\text { интерес }\end{array}$ & $\begin{array}{c}\text { Форма } \\
\text { реализации }\end{array}$ & $\begin{array}{c}\text { Хозяйственный } \\
\text { интерес }\end{array}$ & $\begin{array}{c}\text { Форма } \\
\text { реализации }\end{array}$ \\
\hline $\begin{array}{l}\text { Бизнес } \\
\text { (собственник) }\end{array}$ & $\begin{array}{l}\text { Долгосрочный вос- } \\
\text { производственный } \\
\text { интерес }\end{array}$ & $\begin{array}{l}\text { Рост капитала, кор- } \\
\text { поративных активов } \\
\text { и прибыли }\end{array}$ & $\begin{array}{l}\text { Краткосрочный, не } \\
\text { связанный с вос- } \\
\text { производством }\end{array}$ & $\begin{array}{l}\text { Перевод корпора- } \\
\text { тивных активов в } \\
\text { личные }\end{array}$ \\
\hline
\end{tabular}

Примечание. Составлено авторами. 
Альпидовская, М. Л. Социально-экономическое развитие современной России : Неизбежность устранения антисистемных проявлений / М. Л. Альпидовская // Философия хозяйства. -2017. - № 2 (110). - С. 107-124.

Воронина, Ю. Покусились на чужое. Рейдерство угрожает малому и среднему бизнесу в России / Ю. Воронина // Российская Бизнес-газета. - 2015. - № 26 (1005). - Электрон. текстовые дан. - Режим доступа: https://rg.ru/2015/ 07/07/reyderstvo.html (дата обращения: 01.08.2019). - Загл. с экрана.

Дергачев, В. Рейдерство стало самой частой причиной жалоб бизнеса в Генпрокуратуpy / В. Дергачев. - Электрон. текстовые дан. Режим доступа: https://www.rbc.ru/politics/07/ 02/2017/5898adac9a7947096696dc48 (дата обращения: 01.08.2019). - Загл. с экрана.

Заключение Счетной палаты Российской Федерации на отчет об исполнении федерального бюджета за 2017 год. - М. : [б. и.], 2018. - Электрон. текстовые дан. - Режим доступа: http:// audit.gov.ru/upload/iblock/999/99941 bef8cfcd18e7e10d5e8630f70bb.pdf(дата обращения: 01.08.2019). - Загл. с экрана.

Капелюшников, Р. И. Незащищенность прав собственности и ее экономические последствия: российский опыт / Р. И. Капелюшников // Журнал Новой экономической ассоциации. -2012. - № 1 (13). - С. 150-153.

Карасева, Л. А. Институционализация экономических интересов в социально-экономическом проектировании развития территорий / Л. А. Карасева, А. М. Зинатулин, М. Р. Топалян // Проблемы развития территории. 2018. - № 1. - С. 42-56.

Кириленко, Г. Г. Краткий философский словарь / Г. Г. Кириленко, Е. В. Шевцов. - М. : АСТ : Слово, 2010. - 480 с.

Кричевский, Н. Постпикалевская Россия: новая политико-экономическая реальность / Н. Кричевский. - М. : [б. и.], 2009. - 45 с. - Электрон. текстовые дан. - Режим доступа: http:// www.krichevsky.ru/publikatsii/11-articles/333 (дата обращения: 01.08.2019). - Загл. с экрана.

Стомпелева, Е. С. Особенности развития системы экономических интересов в воспроизводственном аспекте российской экономики / Е. С. Стомпелева // Теоретическая экономика. - 2017. - № 6 (42). - С. 117-125. Электрон. текстовые дан. - Режим доступа: https://old.ystu.ru/download/TheorEconom/ 6-2017.pdf (дата обращения: 01.08.2019). Загл. с экрана.

Фадеева, А. Шохин увидел возможность повторения перестройки в России / А. Фадеева, Н. Демчен- ко. - Электрон. текстовые дан. - Режим доступа: https://www.rbc.ru/business/07/06/2019/ 5cf9fc7a9a79479b5c9f2615?utm source $=$ yxnews\&utm_medium=desktop (дата обращения: 01.08.2019). - Загл. с экрана.

Шваб, К. Четвертая промышленная революция : пер. с англ. / К. Шваб. - М. : Изд-во «Э», 2017. $208 \mathrm{c}$.

Экономические субъекты постсоветской России (институциональный анализ): десять лет спустя. В 3 ч. Ч. 1. Российские домохозяйства / под ред. Р. М. Нуреева.- М. : Моск. обществ. науч. фонд, 2010. - 196 с. - (Серия «Научные доклады: независимый экономический анализ» ; № 212).

The World Bank. - Electronic text data. - Mode of access: https://www.worldbank.org. - Title from screen.

\section{REFERENCES}

Alpidovskaya M.L., Tsikin A.M. Konkurentosposobnost natsionalnoy ekonomiki: strategii razvitiya: monografiya [Competitiveness of the National Economy: Development Strategy. Monograph]. Tver, Tverskoy gosudarstvennyy universitet, 2018.192p.

Alpidovskaya M.L. Sotsialno-ekonomicheskoe razvitie sovremennoy Rossii: Neizbezhnost ustraneniya antisistemnykh proyavleniy [The SocioEconomic Development of the Modern Russia: The Inevitability of the Troubleshooting of the Anti-systemic Manifestations]. Filosofiya khozyaystva [Philosophy of Economy], 2017, no. 2 (110), pp. 107-124.

Voronina Yu. Pokusilis na chuzhoe. Reyderstvo ugrozhaet malomu i srednemu biznesu v Rossii [Encroached on Someone Else's. Raiding Threatens Small and Medium-Sized Businesses in Russia]. Rossiyskaya Biznes-gazeta, 2015, no. 26 (1005). URL: https://rg.ru/2015/07/07/ reyderstvo.html (accessed 1 August 2019).

Dergachev V. Reyderstvo stalo samoy chastoy prichinoy zhalob biznesa $v$ Genprokuraturu [Raider Attacks Became the Most Frequent Cause of Business Complaints to the Prosecutor General's Office]. URL: https://www.rbc.ru/ politics/07/02/2017/5898adac9a7947096696dc48 (accessed 1 August 2019).

Zaklyuchenie Schetnoy palaty Rossiyskoy Federatsii na otchet ob ispolnenii federalnogo byudzheta za 2017 god [Conclusion of the Accounts Chamber of the Russian Federation on the Report on the Execution of the Federal Budget for 2017]. Moscow, 2018. URL: http:// 
audit.gov.ru/upload/iblock/999/99941 bef8cfcd18e7e10d5e8630f70bb.pdf (accessed 1 August 2019).

Kapelyushnikov R.I. Nezashchishchennost prav sobstvennosti i ee ekonomicheskie posledstviya: rossiyskiy opyt [Insecurity of Property Rights and Its Economic Consequences: Russian Experience]. Zhurnal Novoy ekonomicheskoy assotsiatsii [Journal of the New Economic Association], 2012, no. 1 (13), pp. 150-153.

Karaseva L.A., Zinatulin A.M., Topalyan M.R. Institutsionalizatsiya ekonomicheskikh interesov v sotsialno-ekonomicheskom proektirovanii razvitiya territoriy [Institutionalization of Economic Interests in Socio-Economic Planning of Territorial Development]. Problemy razvitiya territorii [Problems of Territory's Development], 2018, no. 1, pp. 42-56.

Kirilenko G.G., Shevtsov E.V. Kratkiy filosofskiy slovar [Short Philosophical Dictionary]. Moscow, AST Publ., Slovo Publ., 2010. 480 p.

Krichevskiy N. Postpikalevskaya Rossiya: novaya politiko-ekonomicheskaya realnost [Russia in Postpikalev Period: A New Political and Economic Reality]. Moscow, 2009. 45 p. URL: http://www.krichevsky.ru/publikatsii/11-articles/ 333 (accessed 1 August 2019).

Stompeleva E.S. Osobennosti razvitiya sistemy ekonomicheskikh interesov v vosproizvodstvennom aspekte rossiyskoy ekonomiki [The Development of a System of Economic Interests in the Production Aspect of the Russian Economy]. Teoreticheskaya ekonomika [The Theoretical Economy], 2017, no. 6 (42), pp. 117-125. URL: https://old.ystu.ru/download/TheorEconom/62017.pdf(accessed 1 August 2019).

Fadeeva A., Demchenko N. Shokhin uvidel vozmozhnost povtoreniya perestroyki v Rossii [Shokhin Saw the Possibility of the Repeat of Perestroika in Russia]. URL: https:/www.rbc.ru/ business/07/06/2019/5cf9fc7a9a79479b5c9f2 615?utm_source=yxnews\&utm_medium $=$ desktop (accessed 1 August 2019).

ShvabK. Chetvertaya promyshlennaya revolyutsiya: per. sangl. [TheFourth Industrial Revolution. Translated from English]. Moscow, Izd-vo «E», 2017. 208 p.

Nureev R.M., ed. Ekonomicheskie subyekty postsovetskoy Rossii (institutsionalnyy analiz): desyat let spustya. V $3 \mathrm{ch}$. Ch. I. Rossiyskie domokhozyaystva [Economic Actors of PostSoviet Russia (Institutional Analysis): Ten Years Later. In 3 Parts. Part I. Russian Households]. Moscow, Moskovskiy obshchestvennyy nauchnyy fond, 2010. 196 p. (Seriya «Nauchnye doklady: nezavisimyy ekonomicheskiy analiz»» [Series "Scientific Reports: Independent Economic Analysis"], no. 212).

The World Bank. URL: https://www.worldbank.org.

\section{Information About the Authors}

Marina L. Alpidovskaya, Doctor of Sciences (Economics), Professor, Department of Economic Theory, Financial University under the Government of the Russian Federation, Prosp. Leningradskiy, 49, 125993 Moscow, Russian Federation, morskaya67@bk.ru, https://orcid.org/0000-0001-9075-9683

Ekaterina S. Stompeleva, Candidate of Sciences (Economics), Senior Lecturer, Department of Economic Theory, Financial University under the Government of the Russian Federation, Prosp. Leningradskiy, 49, 125993 Moscow, Russian Federation, stompeleva@mail.ru, https://orcid.org/0000-0001-9075-2131

\section{Информация об авторах}

Альпидовская Марина Леонидовна, доктор экономических наук, профессор департамента экономической теории, Финансовый университет при Правительстве Российской Федерации, просп. Ленинградский, 49, 125993 г. Москва, Российская Федерация, morskaya67@bk.ru, https://orcid.org/0000-0001-9075-9683

Стомпелева Екатерина Сергеевна, кандидат экономических наук, старший преподаватель департамента экономической теории, Финансовый университет при Правительстве Российской Федерации, просп. Ленинградский, 49, 125993 г. Москва, Российская Федерация, stompeleva@mail.ru, https://orcid.org/0000-0002-9767-2131 